\title{
Upgrading of the Crude Yellow Cake to a Highly Purified Form using Tris (2-ethylhexyl) Phosphate in Presence of EDTA or CDTA
}

\author{
A H Ali, A A Eliwa, M S Hagag* \\ Nuclear Materials Authority, P.O.Box 530, Maadi-Kattameya, Cairo, Egypt \\ * Corresponding author email: mohammedsobbhy@yahoo.com
}

Received: 25 September 2017 / Accepted: 28 September 2017 / Published: 01 October 2017

\begin{abstract}
Upgrading crude yellow cake was done by 0.05 M Tris 2-ethylhexyl Phosphate / kerosene from $5 \mathrm{M}$ nitrate solution. More than $98 \%$ of uranium extracted after 5 stages of contact, shaking time 5 minutes and volume phase ratio $1 / 1$. Uranium stripping efficiency reached $99 \%$ using distilled $\mathrm{H}_{2} \mathrm{O}, 10$ minutes shaking time, $(\mathrm{O} / \mathrm{A})$ ratio $4 / 1$ and three stripping stages. The purity of the produced cakes was enhanced by addition of EDTA or CDTA. The produced cake using TEHP followed by EDTA addition to the stripping solution before uranium precipitation step was the most preferable cake with lower gangues.
\end{abstract}

Keywords: Uranium; Solvent extraction; TEHP; Stripping; EDTA; CDTA.

Abbreviations: (CDTA): 1, 2-Diamino-cyclohexane N, N, N-, N-tetra acetic acid, (EDTA): Ethylene diaminetetracetic acid

\section{Introduction}

The processes of uranium recovery from its containing aqueous systems are of essential scientific and practical importance, not only in the protection of both being health and environmental safety, but also in uranium reutilization resources and potential expansion of nuclear energy [1]. Nuclear grade $\left[\left(\mathrm{NH}_{4}\right)_{2} \mathrm{U}_{2} \mathrm{O}_{7}\right]$ is obtained by dissolving commercial grade uranium concentrates in $\mathrm{HNO}_{3}$ acid, then purified by liquid extraction and precipitated by ammonia solution. It is also transformed to uranium $\mathrm{UO}_{3}$ by calcination and then reduced to uranium dioxide, which is used to fabricate fuel for heavy water reactors. Uranium (VI) may occur in solution as cations or complex anions and so it is easily separated from other elements by the use of either cationic or anionic exchangers [2, 3]. Most metals form stable complexes with EDTA, uranium (VI) is unlike. On passage of an EDTA solution through a column of strongly acid cationicexchanger, uranium (and also $\mathrm{Be}$ and $\mathrm{Ti}$ ) is retained in the column, the other metals passing to the eluate as anionic complexes [4].

Brintzinger and Hesse [5] studied the formation of a salt having the composition $\mathrm{UO}_{2}{ }^{2+} \mathrm{H}_{2}$ $\left(\mathrm{C}_{10} \mathrm{H}_{22} \mathrm{~N}_{2} \mathrm{O}_{8}\right)$. $\mathrm{H}_{2} \mathrm{O}$ by dissolving the solid ethylenediaminetetracetic acid in an aqueous uranyl salt solution which, readily decomposes to yield a precipitate of the hydroxide. Uranyl-EDTA complex is unstable; hydrolyses rapidly and the uranium is precipitated as the $\mathrm{pH}$ is increased this is stated by Cabell [6]. The instability of U(VI)EDTA complex has been utilized by Pribil and 
Vorlicek [7], for uranium precipitation by the addition of ammonium hydroxide in the presence of EDTA, which inhibits other cations deposition. Hara and West [8], have also observed that, when a solution of uranyl nitrate is mixed with a solution of ethylenediaminetetracetic acid, the $\mathrm{pH}$ of the mixture is found to be less than that of either component which emphasis that chelation takes place with a consequent release of hydrogen ions from the organic addendum. By carrying out the high frequency oscillometric-titration of uranium (VI) with EDTA and its salts, they have established that the reacting ratios of metal to addendum are 2:1.

Uranium separation from nitrate solution of monazite mineral leaching by tris(2-ethylhexylphosphate) (TEHP) in comparison with tri-butylphosphate (TBP) dissolved in $\mathrm{n}$-paraffin under different operating conditions such as $\mathrm{HNO}_{3}$ acid, extractant and metal ion concentrations etc. was done by Biswas et al [9]. Uranium distribution ratio $\left(\mathrm{D}_{\mathrm{U}}\right)$ is increased with increasing acidity up to $5 \mathrm{M}$ $\mathrm{HNO}_{3}$ after that a reduction is observed. The separation factors of uranium upon other metal ions (M) are good for TEHP than TBP at all $\mathrm{HNO}_{3}$ acid concentrations. The data used in the construction of McCabe-Thiele diagrams for the recovery uranium by TEHP as the extractant was taken from batch solvent extraction experiments. A process flow sheet has been proposed with $0.2 \mathrm{M}$ TEHP in $\mathrm{n}$-paraffin as solvent for the recovery of $\mathrm{U}(\mathrm{VI})$ from simulated monazite nitrate leach solution. Among several methods for uranium separation is solvent extraction [10-20] and ionic exchanger resins [20,21] being considered as the simplest, applicable and the cheapest one depending on uranium ores grade. Several solvents were used for either yellow cake purification or uranium extraction such tri-butylphosphate, tri-capryl-methyl- ammonium chloride, di-nonyl phenyl phosphoric acid, Cyanex 272 and tri-ethyl-hexyl-phosphate, [9,10, 12-15] which varied in its selectivity and costs, among all of these solvents; organophosphorus solvents came being exceedingly used in respect of its low price in comparable to other solvent and more being selective.

TEHP $[9,15]$ in regarding with other organophosphrous solvent shows very high selectivity and potentiality to be used in uranium extraction in only one publication and as an ionophore in potentiometric sensor for uranium determination with high accuracy and wide detection limit and life span for uranium potentiometric sensor [9], so it was recommended and demand as simple low price solvent for production of highly purified yellow cake prior to enrichment processing uranium without any more upgrading processes.

In this concern we utilize the high selectivity and potentiality of TEHP, complexes stability between EDTA or CDTA with the impurities present in our product and the instability of uranium-EDTA or CDTA complexes to get highly purified yellow cake or nuclear grade material.

\section{Experimental}

\subsection{Chemicals, Reagents and Instrumentations}

\subsubsection{Reagents}

All chemicals and reagents used in this work such as (TEHP, Nitric acid, Sodium salt of EDTA and CDTA) were in analytical grade unless otherwise stated. Double distilled water was used in all solutions preparations. The extraction and stripping experiments for uranium were conducted using $50 \mathrm{~mL}$ glass beaker and the agitation was performed using hot plate magnetic stirrer.

\subsubsection{Instruments and Analysis}

HAANA pH-mV-temp pH-meter, provided with H11270 combination electrode and thermometer sensor made from stainless steel used for measuring hydrogen ion concentration of the different solutions, UV-Vis Shimadzu 1601 used for all spectrophotometric determination such as uranium which was analyzed in all the different working aqueous phases using Arsenazo III method [22]. An atomic absorption model G.B.C.A.A(using a PHILIPS PW 3710/ 31 diffractometer with automatic sample changer PW 1775, 21 position, scintillation counter, $\mathrm{Cu}$ - target tube and $\mathrm{Ni}$ filter.), was used for measuring trace elements. X-ray fluorescence technique (XRF Model geol-gsx3222), was applied for the quantitative determination of the trace elements. 
Ali et al., J. Mod. Mater;; Vol. 4, Issue 1, pp: 37-47, 2017

\subsection{Preparation of Uranyl Nitrate Stock Solution}

The uranyl nitrate stock solution which used in this study was prepared as following: $50 \mathrm{~g}$ of the crude yellow cake was dissolved by using concentrated nitric acid and then adding distilled water till reach $1 \mathrm{~L}$ with $5 \mathrm{M}$ nitric acid as a final nitric acid concentration with $36200 \mathrm{mg} \mathrm{U} / \mathrm{L}$. The average chemical composition of the crude yellow cake is shown in Table 1.

\subsection{Experimental of Crude Yellow Cake Purification Using TEHP}

Lab extraction experiments were performed on the uranyl nitrate stock solution to identify the optimum extraction parameters. Tris(2-ethylhexyl) phosphate (TEHP) dissolved in kerosene was used as an organic phase in the uranium extraction process from the previously prepared uranium stock solution. The factors, which control the extraction process, were studied in detail, which were; the effect of diluents used, TEHP concentration, shaking time and organic to aqueous phase ratio $(\mathrm{O} / \mathrm{A}) \mathrm{v} / \mathrm{v}$.

The mixture from the stock solution and the organic (TEHP) was stirred vigorously in $50 \mathrm{~mL}$ beaker using magnetic stirrer with a fixed stirring speed of $500 \mathrm{rpm}$ and at room temperature. The mixture was then transferred to a separating funnel and allowed to be settled down. The aqueous and organic phases were separated and the aqueous samples were analyzed against its uranium content.

The concentration of uranium in the organic phase was calculated by the difference of its respective concentrations in the aqueous phases before and after extraction. On the other side, the extraction efficiency was calculated according to the following equation:

Extraction efficiency, \%

$=\frac{\text { Original U conc. in Aq. }- \text { Remained U conc. in Aq. }}{\text { Original U conc. in Aq. }} \times 100$

\subsection{Experimental of Uranium Stripping from The Loaded Organic "TEHP"}

Several experiments were performed on the loaded TEHP organic solution to identify the preferable stripping conditions. A mixture from the loaded organic and the stripping aqueous agent (distilled water) was stirred vigorously in 50 $\mathrm{mL}$ beaker using magnetic stirrer with a fixed stirring speed of $500 \mathrm{rpm}$ and at room temperature. The mixture was then transferred to a separating funnel and allowed to be settled down. The aqueous and organic phases were separated and the aqueous samples were analyzed against its uranium content. The factors controlling the stripping process were studied as following, the effect of shaking time, effect of phase ratio $\left(\mathrm{V}_{\mathrm{O}} / \mathrm{V}_{\mathrm{A}}\right)$ and number of contacts.

\subsection{Yellow Cake Precipitation and Characterization}

The uranium content in the stripping solution was precipitated by hydrogen peroxide additions to the stripping solution of $\mathrm{pH}$ 2.0. The precipitated slurry should be allowed to stand for a reaction time of 6-8 hours to achieve complete precipitation. The precipitated cake after several washing steps by using acidified distilled water of $\mathrm{pH} 2.0$ and having $1 \% \mathrm{H}_{2} \mathrm{O}_{2}$ was finally undergoes to drying at $110^{\circ} \mathrm{C}$.

\section{Results and Discussion}

\subsection{Results and Discussion of Extraction Process of Uranium with TEHP}

\subsubsection{Effect of TEHP Concentration}

A series of extraction experiments were carried out by varying the concentration of TEHP from $0.05-0.5 \mathrm{M}$ in kerosene as a diluent at room temperature, shaking time 15 minutes, organic to aqueous phase ratio $\left(\mathrm{V}_{\mathrm{O}} / \mathrm{V}_{\mathrm{A}}\right)$ 1/1, $5 \mathrm{M} \mathrm{HNO}_{3}$ concentration and the initial concentration of uranium was $36200 \mathrm{mg} / \mathrm{L}$. The extraction efficiency and loading capacity results are represented through Figure 1.

From the results, the uranium extraction efficiency and loading capacity increases by increase the organic molarity from 0.05- 0.5. But it was noticed that, the extraction of the other undesirable gangues was increased sharply by increasing the organic concentration, this is because the concentration of the TEHP has doubled ten times while loading capacity was doubled three times only, which allowed to withdraw more impurities. Therefore,0.05 M could be considered the optimum concentration. 


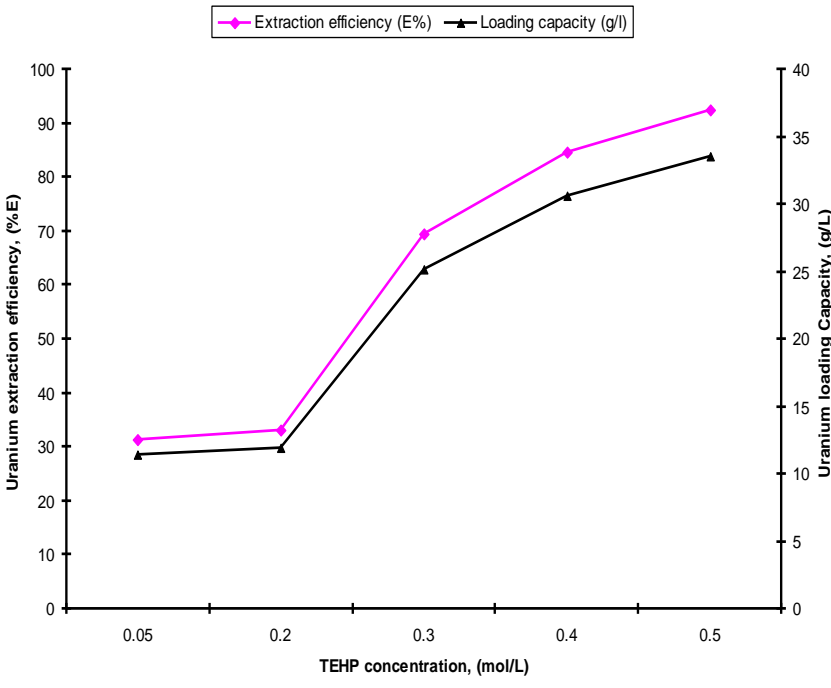

Figure 1: Effect of TEHP concentration on the uranium extraction efficiency and loading capacity

\subsubsection{Effect of Shaking Time}

To study the effect of shaking time on uranium extraction efficiency and loading capacity from its nitrate stock solution (with $36200 \mathrm{mg} / \mathrm{L}$ initial uranium concentration) $5 \mathrm{~mL}$ from uranyl nitrate stock was agitated strongly with $5 \mathrm{~mL}(0.05 \mathrm{M}$ TEHP/ kerosene) in $50 \mathrm{~mL}$ beaker using magnetic agitation for intervals extended from 1 30 minutes and at $\left(25 \pm 2{ }^{\circ} \mathrm{C}\right)$. The phases were separated after transferring the mix to a separating funnel and allowed to be settled down. The aqueous samples were analyzed; the concentrations of uranium in the organic phases have been calculated by the difference of their respective concentrations in the aqueous phases. The obtained results revealed that no significant effect can be noticed for a shaking time more than 5 minutes as shown from Figure 2 and so; shaking time of 5 minutes is quite efficient for uranium extraction where the extraction efficiency reached about $32 \%$ after that it is almost constant.

\subsubsection{Effect of Phase Ratio (O/A)}

The effect of organic- aqueous ratio on the extraction efficiency of U(VI) using 0.05 mole/ LTEHP in kerosene was carried out over the range $1 / 1$ to $1 / 8$ by volume with $36200 \mathrm{mg} / \mathrm{L}$ initial uranium concentration at room temperature for 5 minutes. From the obtained results as shown in Figure 3, it was revealed that although the extraction efficiency and loading capacity

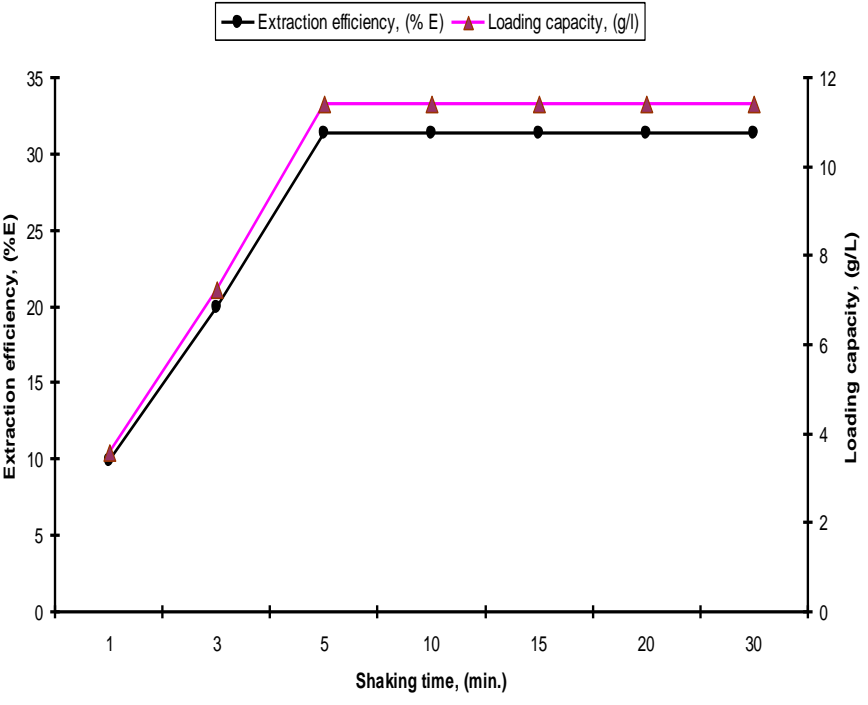

Figure 2: Effect of shaking time on uranium extraction efficiency and loading capacity

increased as phase ratio increased, but the phase ratio $1 / 1$ could be considered the optimum $\mathrm{O} / \mathrm{A}$ ratio because of the produced yellow cake in case of lower phase ratios is purer than that produced at higher ones. This is because the concentration of the TEHP has doubled eight times while loading capacity was doubled three times only, which allowed to withdraw more impurities.

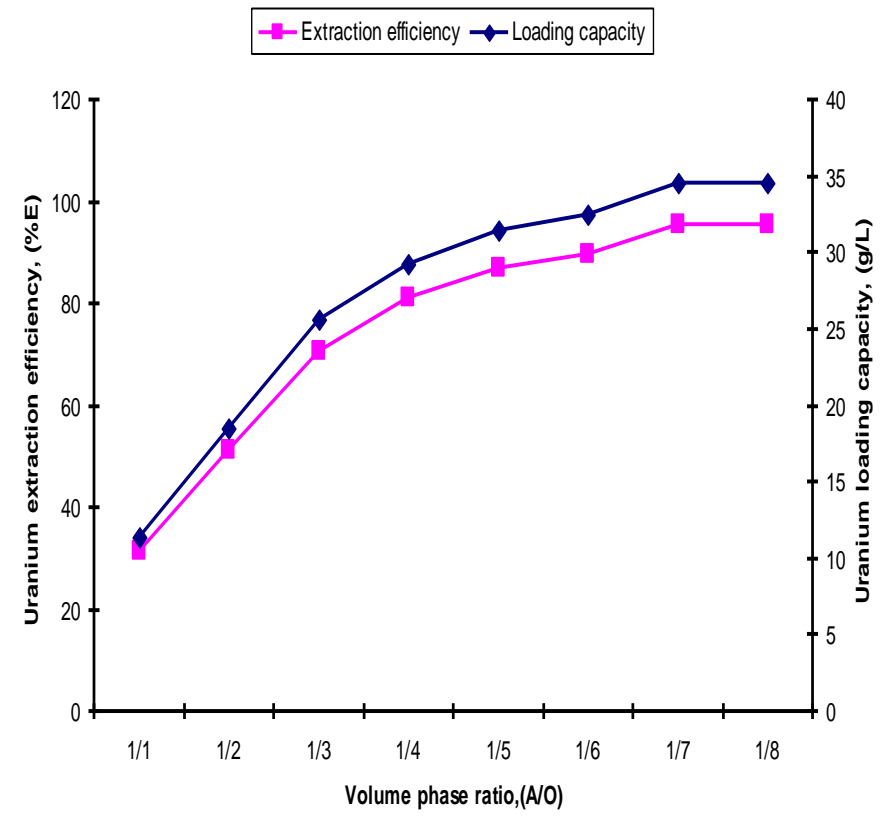

Figure 3: Effect of volume phase ratio (O/A) on uranium extraction efficiency and loading capacity 
DExtraction efficiency, (\% E) D Loading capacity, (g/l)

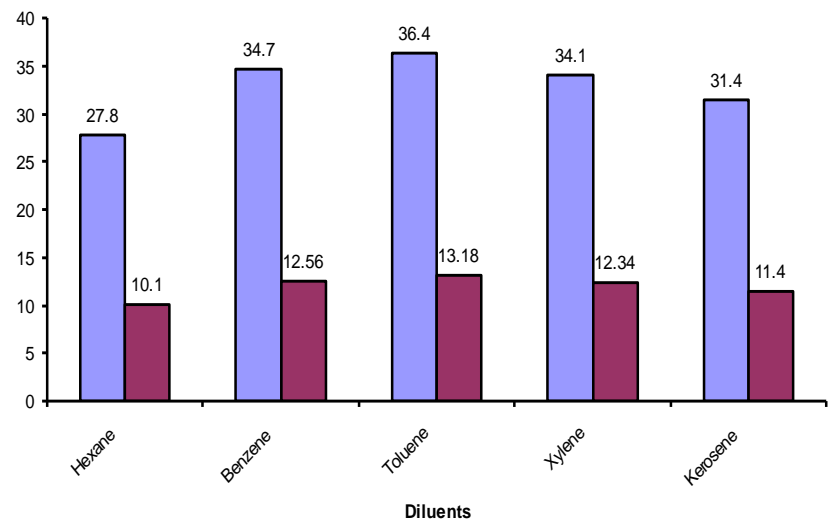

Figure 4: Effect of organic diluents on uranium extraction efficiency and loading capacity

\subsubsection{Effect of Organic Diluents Type}

To study the influence of used diluent type on the extraction of metals according to both physical and chemical interactions occurred between diluents and extractants, various diluents such as benzene, hexane, toluene, xylene and kerosene were tested to estimate their adequacy for extraction of $\mathrm{U}(\mathrm{VI})$ with TEHP. Figure 4 represented the results of uranium extraction; the best extraction yield (36.4\%) was gained by using toluene as diluent. But for economic considerations kerosene was used. Usually the dielectric constant of organic diluents was utilized to interpret the influence of organic diluents on extraction. But in this experiment, it seems that the extraction efficiency was independent on dielectric constant. Maybe other factors including the solubility of diluents in aqueous, sterichindrance of diluents and so on influence the extraction. Hence, it could not be explained only on the base of polarity of diluents.

\subsubsection{Effect of Number of Aqueous Contact}

To get all uranium remained in aqueous phase (raffinate) from the first contact we study the number of contacts of the aqueous phase. In this study, a fresh organic solvent (0.05 M TEHP in kerosene) contacted with remained aqueous feed (raffinate), at the optimum conditions previously determined as, shaking time 5 minutes, room temperature and keeping phase ratio $(\mathrm{O} / \mathrm{A}) 1 / 1$, the aqueous and organic phases were separated and then analyzed for uranium

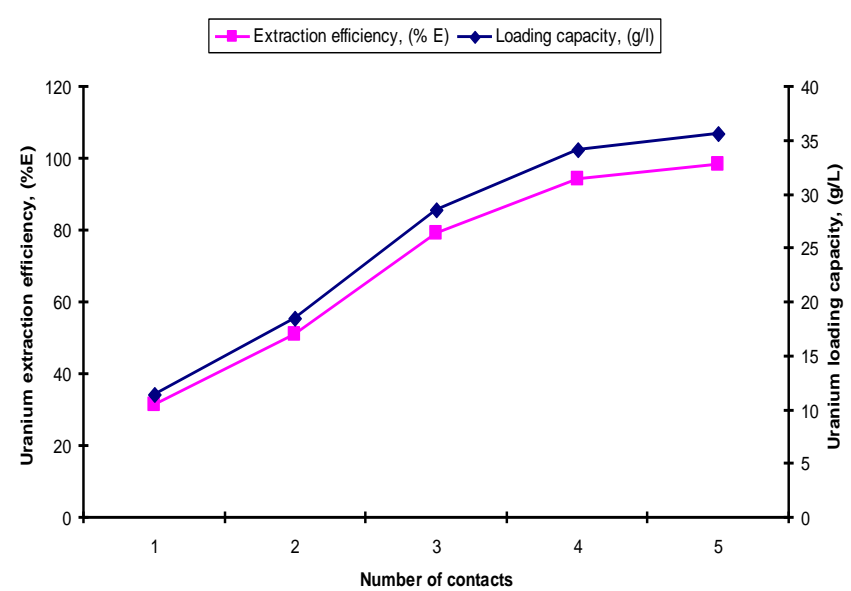

Figure 5: Effect of number of aqueous contacts on uranium extraction efficiency and loading capacity

extracted. The results illustrated below on Figure 5 , a complete uranium extraction by using THEP was achieved by applying 5 practical extraction stages under the fixed conditions.

\subsubsection{Effect of $\mathrm{HNO}_{3}$ Concentration}

The $\mathrm{pH}$ of aqueous solution is one of the most important factors influencing the extraction process. In this experiment, the influence of concentration of $\mathrm{HNO}_{3}$ on the extraction of uranium was investigated. The concentration of $\mathrm{HNO}_{3}$ varied from 2 to $10 \mathrm{M}$; while keeping the other conditions constant as previously determined. Figure 6 showed that change in concentration of $\mathrm{HNO}_{3}$ significantly affects the extraction. Values of loading capacity of TEHP rapidly increases from 2 to $5 \mathrm{M}$, and it reaches the maximum value at about $5 \mathrm{M} \mathrm{HNO}_{3}$ solution, and then it decreases sharply by increasing the nitric acid molarity over $5 \mathrm{M}$ till reach $10 \mathrm{M}$.

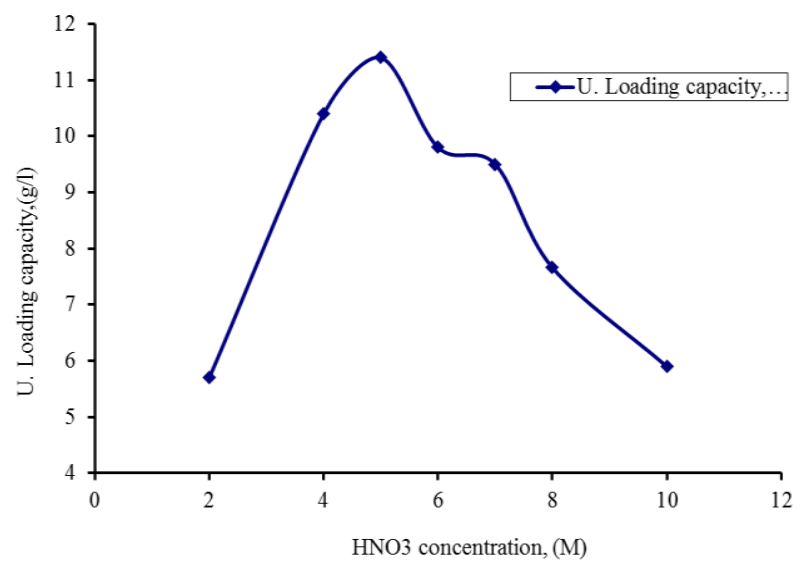

Figure 6: Effect of HNO3 concentration on uranium loading capacity 
$\rightarrow$ Extraction efficiency, $(\% \mathrm{E}) \multimap$ Loading capacity, $(\mathrm{g} / \mathrm{l})$

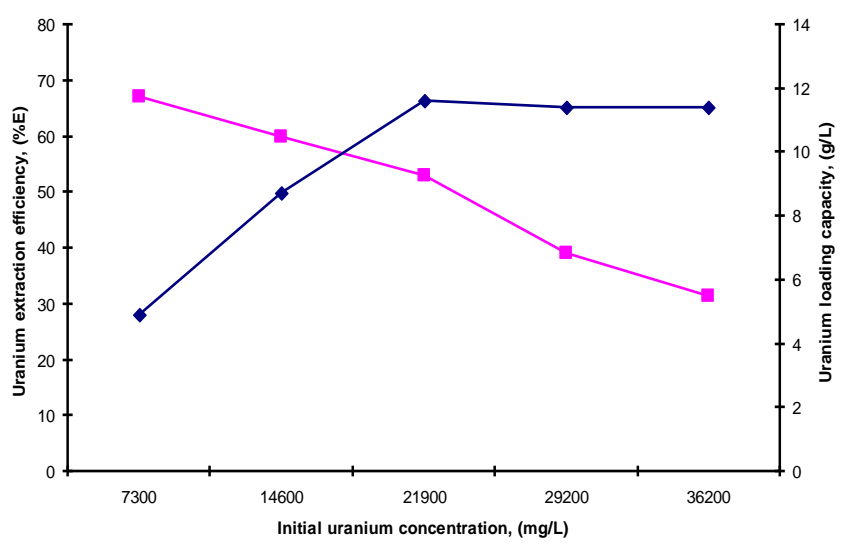

Figure 7: Effect of initial uranium concentration on its extraction efficiency and loading capacity

\subsubsection{Effect of Initial Uranium Concentration}

The effect of uranium concentration was studied by using different uranium solutions varying from 7300 to $36200 \mathrm{mg} / \mathrm{L}$ under the following conditions: $0.05 \mathrm{M}$ TEHP concentration in kerosene, 5 minutes shaking time, $5 \mathrm{M} \mathrm{HNO}_{3}$ concentrations and at phase ratio $(\mathrm{O} / \mathrm{A}) 1 / 1$. From the plotted results shown in Figure 7 , it is clear that extraction efficiency increased as uranium initial concentration decreases while loading capacity of TEHP gradually increased as uranium initial concentration increased till it reached saturation at about $11.4 \mathrm{~g} / \mathrm{L}$.

\subsection{Results and Discussion of Stripping Process of Uranium from Loaded TEHP}

In any extraction process it is necessary to backextract the metal ion from the loaded organic phase. A loaded organic solution containing U(VI) after extraction was employed for stripping tests with double distilled wateras stripping agent at certain conditions. The relevant factors for uranium stripping have been studied which include:

\subsubsection{Effect of Phase Ratio (A/O)}

The effect of phase ratio was studied using different phase ratios $\left(\mathrm{V}_{\mathrm{A}} / \mathrm{V}_{\mathrm{O}}\right)$ ranged from $(6 / 1$ to $1 / 5)$ at room temperature and shaking time for 10 minutes using double distilled water. The obtained results are plotted on Figure 8. From these results, it is clear that by decreasing the aqueous phase $\left(\mathrm{V}_{\mathrm{A}}\right)$ than the organic phase $\left(\mathrm{V}_{\mathrm{O}}\right)$

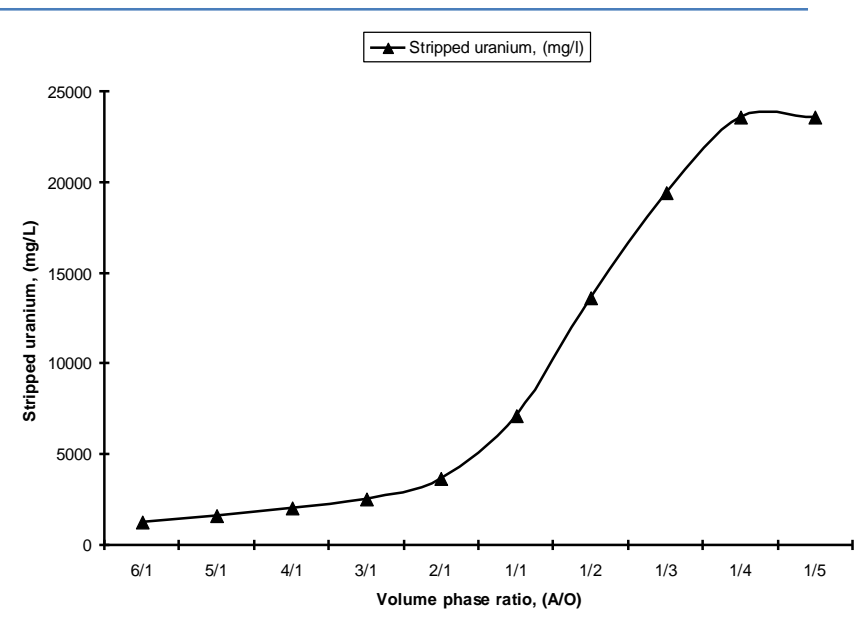

Figure 8: Effect of volume phase ratio $(A / O)$ on uranium stripping efficiency from loaded TEHP

from $6 / 1$ to $1 / 4\left(V_{\mathrm{A}} / \mathrm{V}_{\mathrm{O}}\right)$, the stripping efficiency or the amount of stripped uranium increased sharply, this is due to the dilution factor. The stripping efficiency increased until it reach $1 / 4$ phase ratio $\left(\mathrm{V}_{\mathrm{A}} / \mathrm{V}_{\mathrm{O}}\right)$ and so it considered the best. After that it is almost constant.

\subsubsection{Effect of Shaking Time}

A series of experiments was performed to study the effect of shaking time on the stripping efficiency of uranium from loaded TEHP by varying the time from 1 to 20 minute, while keeping the operating conditions constant as phase ratio $\left(\mathrm{V}_{\mathrm{A}} / \mathrm{V}_{\mathrm{O}}\right)$ of $1 / 4$ and at room temperature. From the obtained results represented on Figure 9, it is clear that shaking time of 10 minutes is the optimum time for stripping efficiency of uranium.

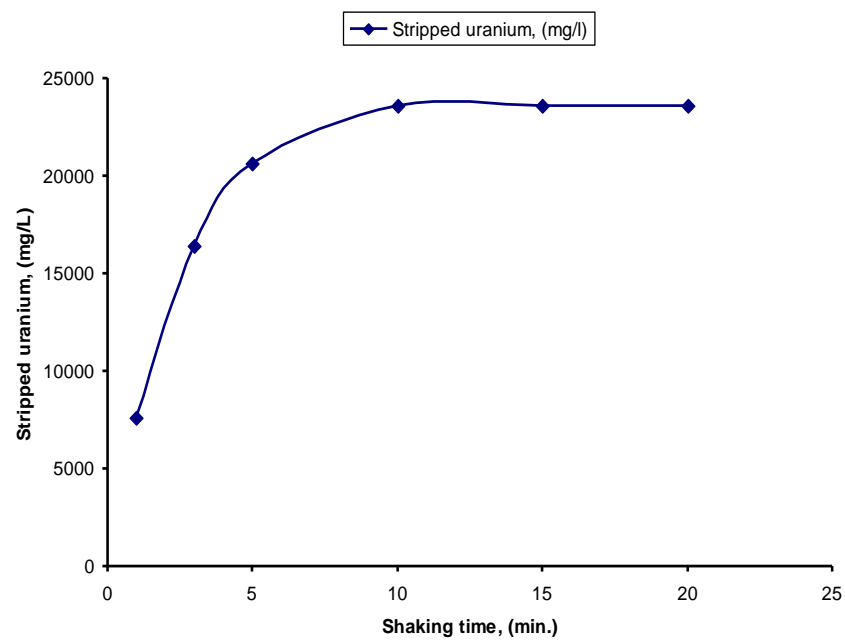

Figure 9: Effect of shaking time on uranium stripping efficiency from loaded TEHP 


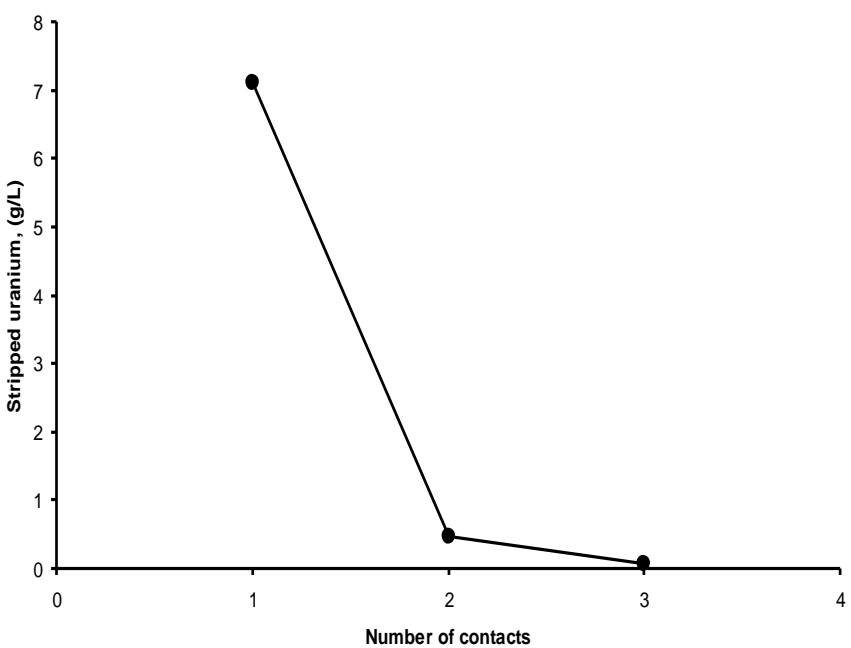

Figure 10: Effect of number of organic contacts on uranium stripping efficiency from loaded TEHP

\subsubsection{Effect of Number of Contacts}

In order to re-extract all uranium from loaded TEHP, the loaded organic is contacted several times with fresh aqueous (distilled water), at the following operating conditions as, shaking time 10 minutes, room temperature and phase ratio $\left(V_{A}\right.$ $\left./ \mathrm{V}_{\mathrm{O}}\right) 1 / 4$, the aqueous and organic phases were separated and then analyzed for uranium reextracted. From the results illustrated below on Figure 10, it is clear that about 3 practical stages are quite suitable for uranium stripping from loaded TEHP using distilled water.

\subsection{Results of Adding EDTA or CDTA on the Purity of Refined Yellow Cake}

\subsubsection{Effect of Addition of EDTA or CDTA on the Purity of Refined Yellow Cake}

Finally, a series of experiments were performed to produce a refined cake as shown in Table 2 by using TEHP as an organic solvent with or without some addition of EDTA or CDTA to identify their effect on the yellow cake purity, the refined cakes were finally characterized by X-Ray Fluorescence "XRF" and by Atomic absorption spectrophotometer and compared with the crude yellow cake specifications. All XRF and Atomic absorption instruments results were presented in Figures 11-16 and Tables (1, 3). In general, from the results, the purity of the produced cake was enhanced by addition of EDTA or CDTA before the extraction or after the stripping steps than the produced cake without any additions, this due to the complex formed between the gangues and EDTA or CDTA which decrease their extraction on the solvent or their precipitation from the stripping solutions. On the other side, the purified yellow cake produced by using TEHP as an organic solvent followed by EDTA addition to the stripping solution before uranium precipitation step was the most preferable cake according to the highly purified one with lower gangues comparing with the other.

Table 1: XRF-elemental analysis for crude yellow cake and the final refined Y.C. produced in presence or absence of EDTA or CDTA additions

\begin{tabular}{|c|c|c|c|c|c|c|}
\hline $\begin{array}{c}\text { Elem } \\
\text { ent } \\
\text { Oxid } \\
\text { es } \\
(\%)\end{array}$ & $\begin{array}{c}\text { Crude } \\
\text { Y.C. } \\
\text { (Origi } \\
\text { nal) }\end{array}$ & $\begin{array}{c}\text { Final } \\
\text { Y.C. } \\
\text { witho } \\
\text { ut } \\
\text { additi } \\
\text { ons }\end{array}$ & $\begin{array}{l}\text { Final } \\
\text { Y.C., } \\
\text { the } \\
\text { strip } \\
\text { has } \\
\text { EDT } \\
\text { A } \\
\text { addit } \\
\text { ion }\end{array}$ & $\begin{array}{l}\text { Final } \\
\text { Y.C., } \\
\text { the } \\
\text { strip } \\
\text { has } \\
\text { CDT } \\
\text { A } \\
\text { addit } \\
\text { ion }\end{array}$ & $\begin{array}{l}\text { Final } \\
\text { Y.C. } \\
\text { extrac } \\
\text { ted in } \\
\text { prese } \\
\text { nce of } \\
\text { EDT } \\
\text { A }\end{array}$ & $\begin{array}{c}\text { Final } \\
\text { Y.C. } \\
\text { extrac } \\
\text { ted in } \\
\text { prese } \\
\text { nce of } \\
\text { CDT } \\
\text { A }\end{array}$ \\
\hline $\mathrm{U}_{3} \mathrm{O}_{8}$ & 68.92 & 97.75 & 98.87 & 96.54 & 97.30 & 97.17 \\
\hline $\mathrm{P}_{2} \mathrm{O}_{5}$ & -- & 0.02 & -- & 0.39 & 0.28 & 0.16 \\
\hline $\mathrm{SO}_{3}$ & 21.26 & 0.24 & -- & 0.28 & 0.34 & 0.57 \\
\hline $\mathrm{K}_{2} \mathrm{O}$ & 0.29 & 0.18 & -- & -- & -- & 0.09 \\
\hline $\mathrm{CaO}$ & 1.40 & 0.34 & 0.44 & 0.57 & 0.32 & 0.53 \\
\hline $\mathrm{Fe}_{2} \mathrm{O}_{3}$ & 3.30 & 0.07 & 0.03 & 0.17 & 0.15 & 0.09 \\
\hline $\mathrm{NiO}$ & 0.20 & 0.01 & 0.02 & -- & 0.03 & -- \\
\hline $\mathrm{CuO}$ & -- & 0.06 & 0.01 & 0.01 & 0.02 & 0.03 \\
\hline $\mathrm{ZnO}$ & 0.09 & 0.02 & -- & -- & -- & -- \\
\hline $\mathrm{ZrO}_{2}$ & 0.34 & 0.06 & -- & 0.07 & 0.04 & 0.02 \\
\hline $\mathrm{La}_{2} \mathrm{O}_{3}$ & 0.23 & 0.14 & -- & -- & -- & -- \\
\hline $\mathrm{CeO}_{2}$ & 0.19 & 0.13 & 0.13 & 0.19 & -- & 0.12 \\
\hline $\operatorname{Pr}_{6} \mathrm{O}_{11}$ & 0.01 & 0.14 & 0.05 & 0.27 & 0.15 & 0.02 \\
\hline $\mathrm{Gd}_{2} \mathrm{O}_{3}$ & 0.13 & 0.01 & 0.03 & 0.07 & 0.10 & 0.08 \\
\hline $\mathrm{Dy}_{2} \mathrm{O}_{3}$ & 0.01 & 0.05 & -- & -- & -- & 0.06 \\
\hline $\mathrm{Ho}_{2} \mathrm{O}_{3}$ & -- & 0.16 & -- & -- & -- & 0.16 \\
\hline $\mathrm{Yb}_{2} \mathrm{O}_{3}$ & -- & 0.06 & 0.06 & 0.11 & -- & 0.02 \\
\hline $\mathrm{TiO}_{2}$ & -- & -- & 0.08 & -- & 0.12 & -- \\
\hline $\mathrm{MnO}$ & 0.50 & -- & 0.06 & -- & -- & -- \\
\hline $\mathrm{Tm}_{2} \mathrm{O}_{3}$ & 0.01 & -- & 0.01 & 0.04 & 0.05 & 0.07 \\
\hline $\mathrm{MgO}$ & 2.88 & -- & -- & 0.65 & -- & -- \\
\hline $\mathrm{Y}_{2} \mathrm{O}_{3}$ & -- & -- & -- & 0.06 & 0.10 & 0.07 \\
\hline $\begin{array}{c}\mathrm{Nd}_{6} \mathrm{O}_{1} \\
1 \\
\end{array}$ & -- & -- & -- & 0.06 & -- & -- \\
\hline $\mathrm{Sm}_{2} \mathrm{O}_{3}$ & -- & -- & -- & 0.06 & 0.19 & -- \\
\hline $\mathrm{Lu}_{2} \mathrm{O} 3$ & -- & -- & -- & 0.05 & -- & -- \\
\hline $\mathrm{Tb}_{4} \mathrm{O}_{7}$ & 0.21 & -- & -- & -- & 0.12 & 0.07 \\
\hline $\mathrm{Er}_{2} \mathrm{O}_{3}$ & -- & -- & -- & -- & 0.02 & 0.01 \\
\hline $\mathrm{Cr}_{2} \mathrm{O}_{3}$ & 0.22 & -- & -- & -- & -- & -- \\
\hline $\mathrm{SiO}_{2}$ & 0.80 & 0.54 & 0.04 & 0.42 & 0.41 & 0.50 \\
\hline
\end{tabular}




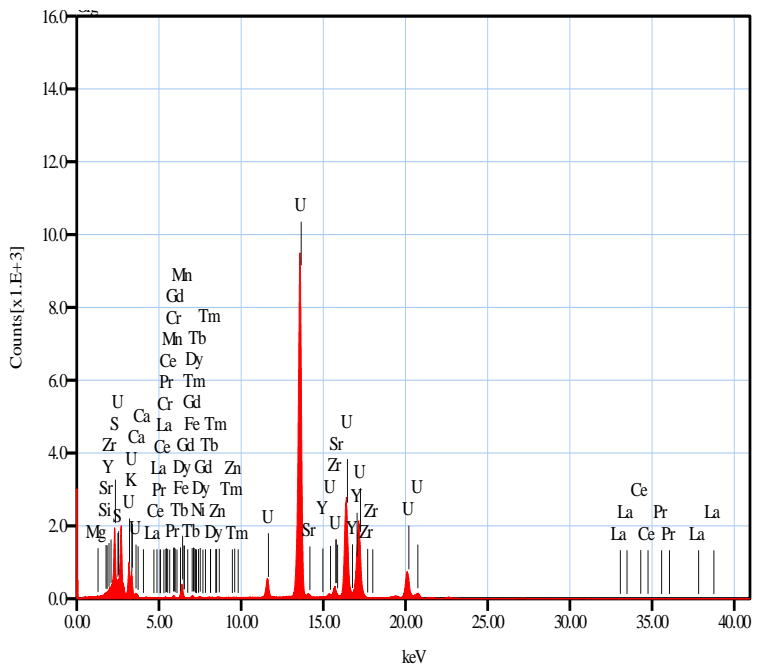

Figure 11: $X R F$ - chart for the crude Y.C

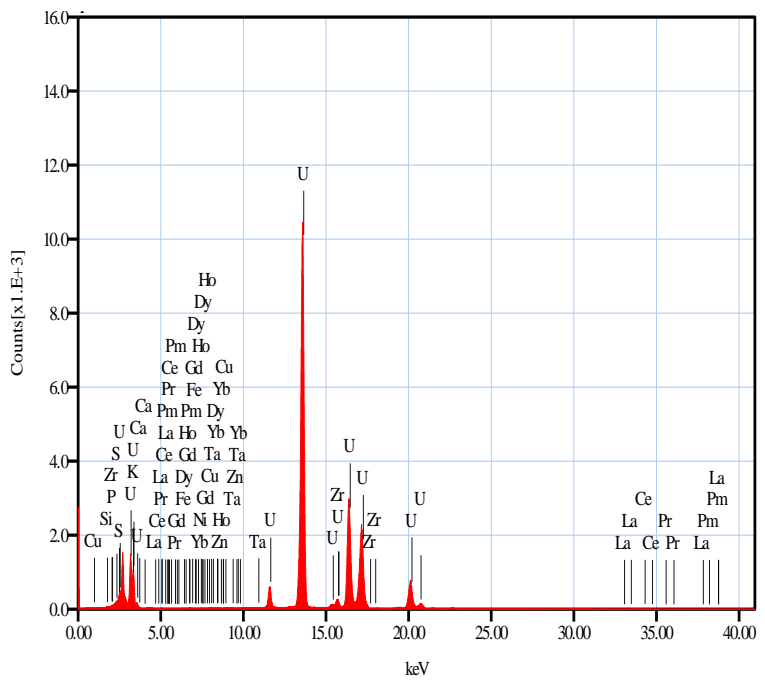

Figure 12: $X R F$ - chart for the purified Y.C. without EDTA or CDTA addition

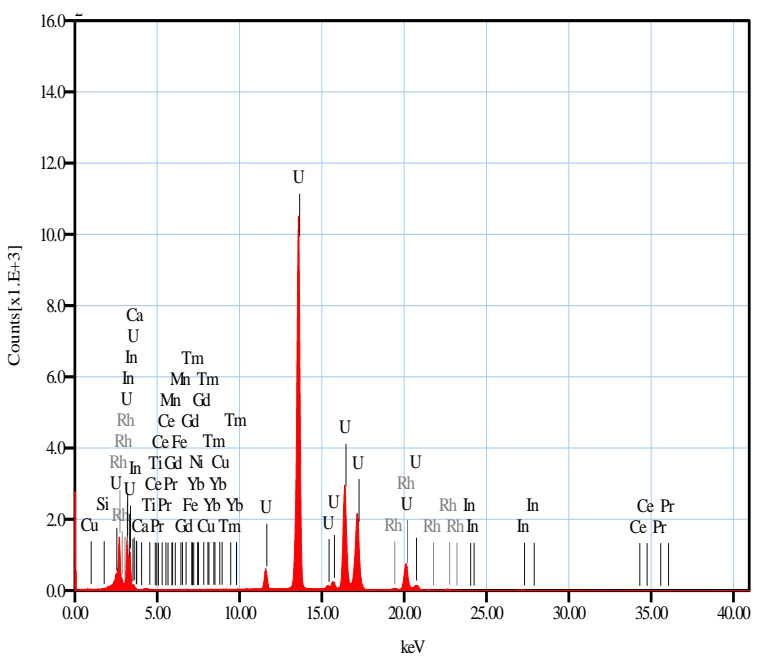

Figure 13: $X R F$ - chart for Final Y.C. stripped in presence of EDTA

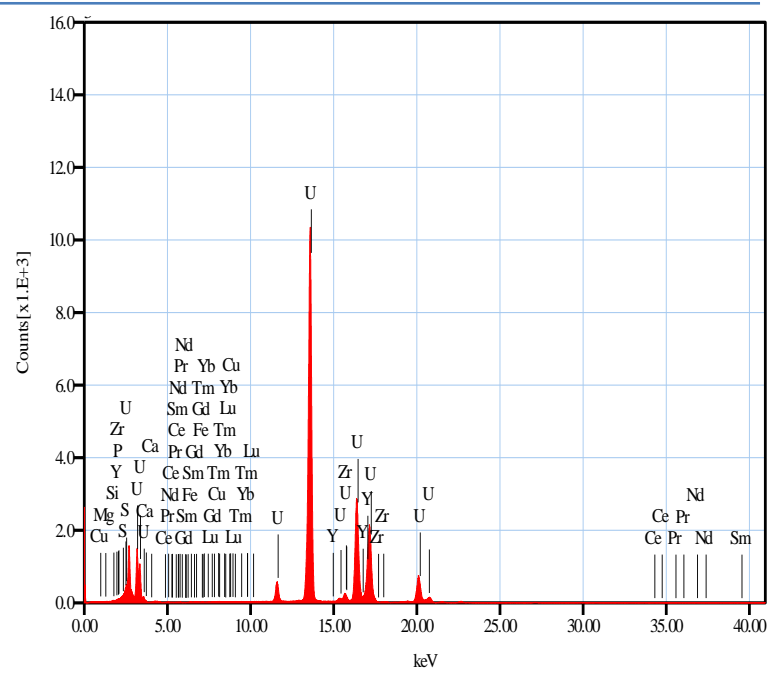

Figure 14: $X R F$ - chart for Final Y.C. stripped in presence of CDTA

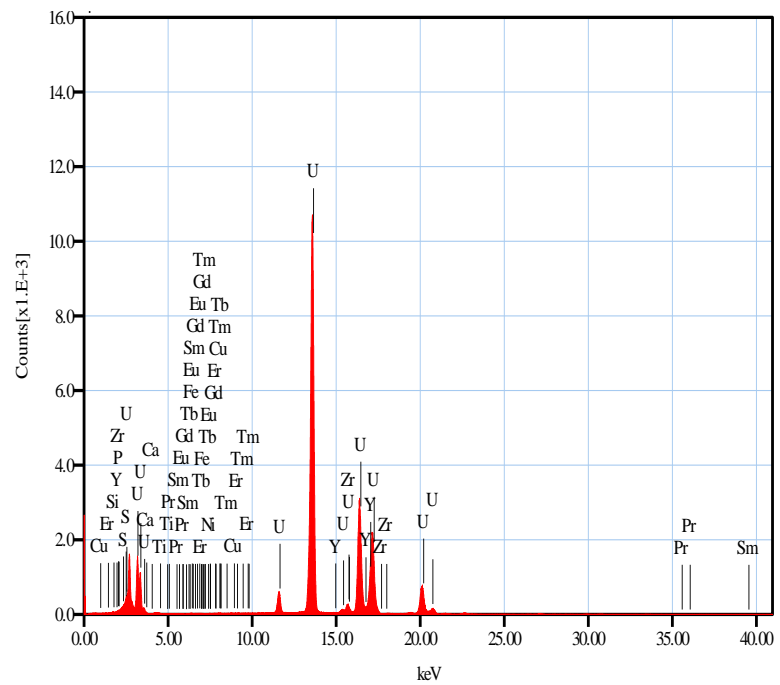

Figure 15: $X R F$ - chart for Final Y.C. extracted in presence of EDTA

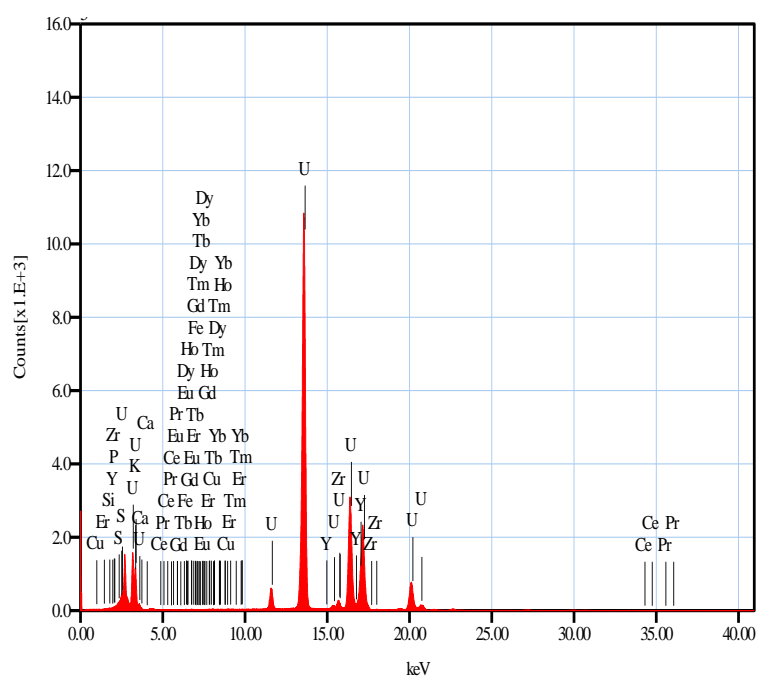

Figure 16: $X R F$ - chart for Final Y.C. extracted in presence of CDTA 
Ali et al., J. Mod. Mater.; Vol. 4, Issue 1, pp: 37-47, 2017

Table 2: Purifying yellow cake experiments by using TEHP with or without using EDTA or CDTA

\begin{tabular}{|c|c|}
\hline Type of cake & Experiment \\
\hline Crude Y.C.(Original) & The original crude yellow cake \\
additions & $\begin{array}{c}\text { The purified Y.C. produced by using TEHP } \\
\text { as a solvent without using EDTA or CDTA } \\
\text { in the extraction or stripping processes }\end{array}$ \\
\hline $\begin{array}{c}\text { Final Y.C.,the strip } \\
\text { has EDTA addition }\end{array}$ & $\begin{array}{c}\text { The purified Y.C. produced by using TEHP } \\
\text { and by adding EDTA to the stripping } \\
\text { solution before U precipitation process } \\
(0.01 \% \text { EDTA conc. in strip soln.) }\end{array}$ \\
\hline $\begin{array}{c}\text { Final Y.C., the strip } \\
\text { has CDTA addition }\end{array}$ & $\begin{array}{c}\text { The purified Y.C. produced by using TEHP } \\
\text { and by adding CDTA to the stripping } \\
\text { solution before U precipitation process } \\
(0.01 \% \text { CDTA conc. in strip soln.) }\end{array}$ \\
\hline $\begin{array}{c}\text { Final Y.C. extracted } \\
\text { in presence of EDTA }\end{array}$ & $\begin{array}{c}\text { The purified Y.C. produced by using TEHP } \\
\text { and by adding EDTA to the leach liquor } \\
\text { before the extraction step (0.01\% EDTA } \\
\text { conc. in liqueur) }\end{array}$ \\
\hline $\begin{array}{c}\text { Final Y.C. extracted } \\
\text { in presence of CDTA }\end{array}$ & $\begin{array}{c}\text { The purified Y.C. produced by using TEHP } \\
\text { and by adding CDTA to the leach liquor } \\
\text { before the extraction step (0.01\% CDTA } \\
\text { conc. in liqueur) }\end{array}$ \\
\hline
\end{tabular}

Table 3: Atomic absorption elemental analysis for crude yellow cake and the final refined Y.C. produced in presence or absence of EDTA or CDTA additions

\begin{tabular}{|c|c|c|c|c|c|c|}
\hline $\begin{array}{c}\text { Elem } \\
\text { ent } \\
(\mathrm{ppm})\end{array}$ & $\begin{array}{c}\text { Crude } \\
\text { Y.C. } \\
\text { (Origi } \\
\text { nal) }\end{array}$ & $\begin{array}{c}\text { Final } \\
\text { Y.C. } \\
\text { witho } \\
\text { ut } \\
\text { additi } \\
\text { ons }\end{array}$ & $\begin{array}{l}\text { Final } \\
\text { Y.C., } \\
\text { the } \\
\text { strip } \\
\text { has } \\
\text { EDT } \\
\text { A } \\
\text { addit } \\
\text { ion }\end{array}$ & $\begin{array}{l}\text { Final } \\
\text { Y.C., } \\
\text { the } \\
\text { strip } \\
\text { has } \\
\text { CDT } \\
\text { A } \\
\text { addit } \\
\text { ion }\end{array}$ & $\begin{array}{c}\text { Final } \\
\text { Y.C. } \\
\text { extrac } \\
\text { ted in } \\
\text { prese } \\
\text { nce of } \\
\text { EDT } \\
\text { A }\end{array}$ & $\begin{array}{c}\text { Final } \\
\text { Y.C. } \\
\text { extrac } \\
\text { ted in } \\
\text { prese } \\
\text { nce of } \\
\text { CDT } \\
\text { A }\end{array}$ \\
\hline $\mathrm{Cd}$ & 0.3 & ND & ND & ND & ND & ND \\
\hline $\mathrm{Mn}$ & $\begin{array}{c}1997 . \\
5\end{array}$ & 2.6 & ND & ND & 137.6 & 109.8 \\
\hline $\mathrm{Cu}$ & $\begin{array}{c}145.7 \\
6\end{array}$ & 5.3 & ND & ND & 125.6 & 3.2 \\
\hline $\mathrm{Fe}$ & $\begin{array}{c}11101 \\
.6\end{array}$ & $\begin{array}{c}1186 . \\
3\end{array}$ & $\begin{array}{c}15.8 \\
4\end{array}$ & 20.2 & $\begin{array}{c}1162 . \\
3\end{array}$ & 833.6 \\
\hline $\mathrm{Pb}$ & 269.6 & ND & ND & 5.3 & 13.8 & 107.8 \\
\hline $\mathrm{Ni}$ & 568.4 & ND & ND & ND & 52.4 & 47.2 \\
\hline $\mathrm{Ti}^{*}$ & 43.6 & ND & ND & ND & ND & ND \\
\hline $\mathrm{Ca}^{*}$ & 2.8 & ND & ND & ND & ND & ND \\
\hline $\mathrm{Si}^{*}$ & 480 & ND & ND & ND & ND & ND \\
\hline $\begin{array}{c}\Sigma \mathrm{RE} \\
\mathrm{E}^{*}\end{array}$ & 6500 & 811.8 & $\begin{array}{c}849 . \\
6\end{array}$ & $\begin{array}{c}1031 \\
.3\end{array}$ & 520 & 460 \\
\hline
\end{tabular}

*Analyzed by spectrophotometric and volumetric methods
The final yellow cake stripped in presence of EDTA, which precipitated by using hydrogen peroxide, was finally identified by X-Ray diffraction pattern using "XRD - Philips PW3710" at the Nuclear Materials Authority. The results are illustrated in Figure 17 and Table 4.

Table 4: X-ray diffraction data of Studtite and Uranium Oxide Hydrate identified into the End Product Uranium Precipitation

\begin{tabular}{|c|c|c|c|c|c|}
\hline \multicolumn{2}{|c|}{ Sample } & \multicolumn{2}{c|}{$\begin{array}{c}\text { Studtite } \\
\mathrm{UO}_{4} .4 \mathrm{H}_{2} \mathrm{O}\end{array}$} & \multicolumn{2}{c|}{$\begin{array}{c}\text { Uranium Oxide } \\
\mathrm{UO}_{4}\end{array} \mathrm{H}_{2} \mathrm{O}$} \\
\hline $\mathrm{dA}^{\mathrm{o}}$ & $\mathrm{I} / \mathrm{I}_{\mathrm{o}}$ & $\mathrm{dA}^{\mathrm{o}}$ & $\mathrm{I} / \mathrm{I}_{\mathrm{o}}$ & $\mathrm{dA}^{\mathrm{o}}$ & $\mathrm{I}_{\mathrm{o}}$ \\
\hline 5.92 & 100 & 5.88 & 100 & - & - \\
5.24 & 54 & - & - & 5.22 & 100 \\
4.37 & 17 & - & - & 4.39 & 35 \\
4.25 & 25 & 4.23 & 12 & - & - \\
3.80 & 25 & - & - & 3.79 & 35 \\
3.54 & 44 & 3.55 & 10 & 3.53 & 35 \\
3.40 & 44 & 3.40 & 20 & - & - \\
3.26 & 8 & - & - & 3.25 & 16 \\
2.96 & 7 & 2.95 & 6 & - & - \\
2.75 & 14 & 2.73 & 6 & 2.75 & 20 \\
2.66 & 15 & 2.648 & 8 & 2.666 & 20 \\
2.61 & 8 & 2.588 & 6 & 2.611 & 10 \\
2.50 & 10 & 2.50 & 6 & - & - \\
2.47 & 13 & 2.451 & 6 & 2.47 & 20 \\
2.40 & 12 & 2.38 & 6 & 2.403 & 16 \\
2.23 & 7 & 2.234 & 6 & - & - \\
2.12 & 8 & 2.118 & 4 & 2.104 & 12 \\
2.01 & 12 & 2.012 & 12 & - & - \\
1.94 & 16 & 1.931 & 8 & 1.953 & 14 \\
1.86 & 4 & 1.844 & 2 & 1.864 & 14 \\
1.76 & 8 & 1.758 & 6 & 1.766 & 6 \\
1.69 & 4 & - & - & 1.693 & 2 \\
1.64 & 5 & 1.639 & 2 & 1.639 & 6 \\
1.57 & 2 & 1.573 & 4 & 1.524 & 2 \\
1.50 & 5 & - & - & 1.494 & 6 \\
\hline
\end{tabular}

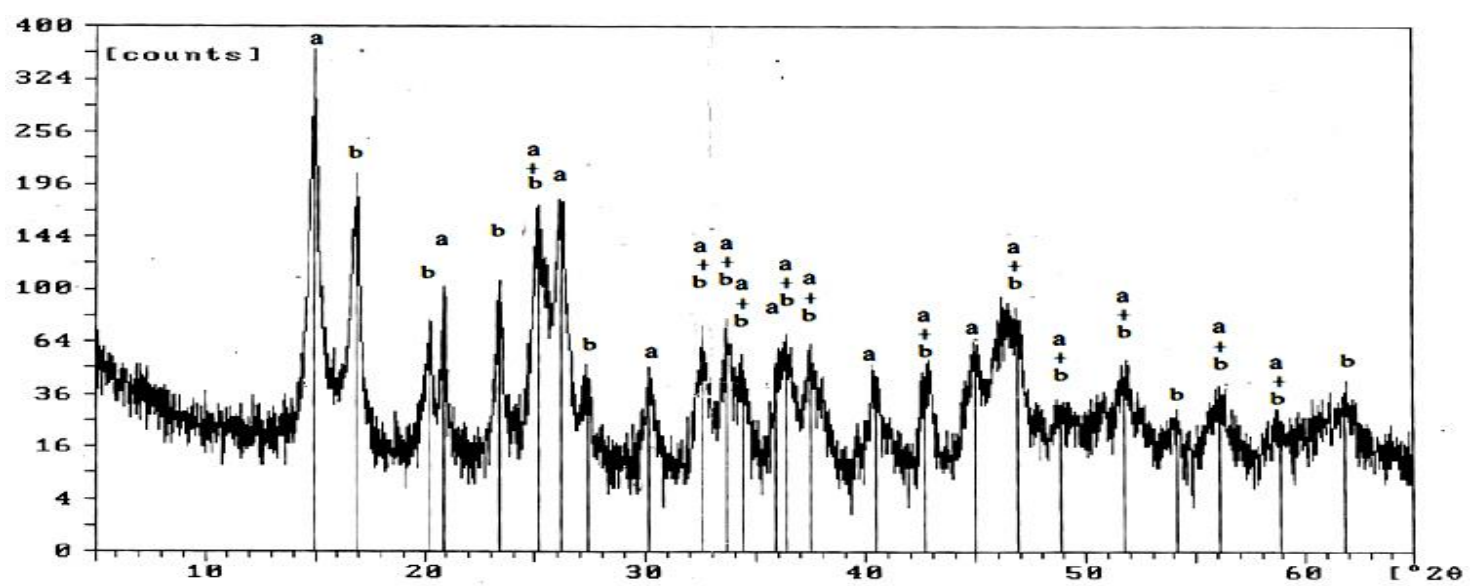

Figure 17: XRD-Chart of Yellow Cake End Product $a=$ Studtite $b=$ Uranium Peroxide 


\section{Conclusions}

A crude uranium cake was collected from different hydrometallurgical uranium recovery processes with about $69 \%$ uranium concentration. Series of refining processes were carried out on the crude yellow cake by using TEHP as an organic solvent. A uranyl nitrate stock solution obtained by dissolving crude yellow cake in $5 \mathrm{M}$ nitric acid was subjected to uranium extraction using 0.05 M TEHP dissolved in kerosene as a diluent. The preferable conditions, which achieve about $97 \%$ uranium extraction efficiency with minimum undesirable gangues extraction, were 0.05 TEHP concentration, 5 minutes shaking time, $1 / 1$ phase ratio $(\mathrm{O} / \mathrm{A}) \mathrm{v} / \mathrm{v}$ and $5 \mathrm{M}$ nitric acid concentration. Complete extraction was achieved by applying after 5 stages of contact between fresh organic and the aqueous. On the other hand, the stripping efficiency of about $99 \%$ from the loaded TEHP was achieved by using a distilled water as a stripping agent with 10 minute shaking time, $1 / 4$ phase ratio $(\mathrm{A} / \mathrm{O})$ and after three stages of stripping.

According to the EDTA or CDTA-gangues complex formation which decrease the gangues extraction by solvent or decrease their precipitating from the strip solution, the purity of the produced cake was enhanced by using EDTA and CDTA additions through the extraction and the stripping steps. Finally, the purified yellow cake produced by using TEHP followed by EDTA addition to the stripping solution before uranium precipitation step was the most preferable cake according to the highly purified one with lower gangues comparing with the other.

\section{How to Cite this Article:}

A. Ali, A. Eliwa, and M. Hagag, "Upgrading of the Crude Yellow Cake to a Highly Purified Form using Tris (2-ethylhexyl) Phosphate in Presence of EDTA or CDTA", J. Mod. Mater., vol. 4, no. 1, pp. 37-47, Oct. 2017.doi: 10.21467/jmm.4.1.37-47

\section{References}

[1] B. Li, L. Ma, Y. Tian, X. d. Yang, J. Li, Ch. Bai, X. y. Yang, Sh. Zhang, Sh. J. Li, Y. d. Jin: "A catechol-like phenolic ligand-functionalized hydrothermal carbon: One-pot synthesis, characterization and sorption behavior toward uranium”. Journal of Hazardous Materials, 271, pp. 41-49, (2014)
[2] F. Tera and J. korkisch: "Separation of uranium by anion exchange", Analytical chimica. Acta 25(1), pp. 222-225, (1961).

[3] F.W.E. Strelow and T.N. van der Walt, T.N.Z.:" Highly accurate determination of trace amounts of uranium in standard reference materials by spectrophotometry with chlorophosphonazo III after complete separation by anion and cation exchange chromatography", Anal. Chem, 306,(2), pp.110-114,(1981).

[4] Z. Sulcek and P. Povondra:" Analytische Schnell methodenzuruntersuchung von Metallen und an organischenRohstoffen XVI. PhotometrisheBestimmung von uranspuren in WassennachVorangehenderAbtrennungamchelataustausc her."Collect. Czech. Chem. Commun, 32, (9), pp. 31403148, 1967.

[5] H. Brintzinger and G. Hesse:" Kupfer-, Nickel and uranyl Verbindungen der Athylenediaminetetraessigsaure, Z, anorg. allg. Chem. 249,(1), 113-118, in German. Cited in pages: 460-477, 1942

[6] M. J. Cabell:" The complexes formed by thorium and uranyl ions with complexones" Analyst. 77, 859-866, 1952

[7] Přibil, R., and T. Vorlíček: POUZITI KOMPLEXONU V CHEMICKE ANALYSE, Chem. Listy46, (4), 216-218, (1952); cf. Z. analyt. Chem. 139, 130 (1953).

[8] R. Hara and PH. W. West: High frequency titrations involving chelation with ethylene di amine tetra acetic acid: Determination of uranyl ion,Analytica Chimica ActaVolume 12, Pages 285-291, (1955).

[9] S. Biswas, P. N. Pathak, D. K. Singh, \& S. B. Roy: Comparative Evaluation of Tri-n-butyl Phosphate (TBP) and Tris(2-ethylhexyl) Phosphate (TEHP) for the Recovery of Uranium from Monazite Leach Solution, Separation Science and Technology, (2013), 48:13

[10] U. Injarean, P. Pichestapong, P. Kewsuwan and J. Laohaphornchaiphan: "Batch Simulation of Multistage Countercurrent Extraction of Uranium in Yellow Cake from Monazite Processing with 5\% TBP/Kerosene " Energy Procedia 56, 129 - 134, ( 2014 )

[11] J. E. Quinn, K. H. Soldenhoff, "process for uranium recovery Cyanex 272" Hydrometallurgy, 152, 7-12, (2015).

[12] M. E. Nasab, "solvent extraction separation of uranium (VI) and thorium (IV) with neutral organo-phosphorous and amine ligand" Fuel, 116, 595-600, (2014).

[13] H. Singh, R. Vijayalakshmi, S.L Mishra, C.K Gupta, "Studies on uranium extraction from phosphoric acid using di-nonyl-phosphoric acid- based synergistic mixtures" Hydrometallurgy, 59,(1),pp. 69-76 , (2001).

[14] D. Das, V.A. Juvekar, V.H. Rupawate, K. Ramprasad, R. Bhattacharya, "Effect of the nature of organo phosphorous moiety on co-extraction of uranium (VI) and mineral acids from aqueous solutions using D2EHPA, PC88A and Cyanex 272 " Hydrometallurgy, 152, 129-138, (2015)

[15] N. M. Sundaramurthi, G. S Desai, V. M. Shinde, "Extraction and separations studies of Uranium (VI) with tris-(2-ethyl hexyl)phosphate" Journal of Radioanalytical and Nuclear Chemistry, 144,(6), 439-445, (1990).

[16] P. K. Mohapatra, D. R. Raut, A. Sengupta: "Extraction of uranyl ion from nitric acid medium using solvent containing TOPO and its mixture with D2EHPA in room temperature ionic liquids" Separation and Purification Technology, 133, 69-75, (2014). 
[17] 17. J.F. Goldenberg, C. Abbruzzese:"Extraction of uranium from heap leach liquor with tri-n-octylamine: Equilibrium data and flow-sheet calculations." International Journal of Mineral Processing, 10, 4, 241254, (1983)

[18] 18. G. Hellé, C. Mariet, G. Cote, "Liquid-liquid extraction of uranium(VI) with Aliquat 336 from $\mathrm{HCl}$ media in microfluidic devices: Combination of microunit operations and online ICP-MS determination" Talanta, 139, 123-131, (2015).

[19] H. Singh, S.L. Mishra, R. Vijayalakshmi, "Uraniumrecovery from phosphoric acid by solventextraction using a synergistic mixture of dinonyl phenyl phosphoric acid and tri- $n$-butyl phosphate" Hydrometallurgy, 73, (1-2), 63-70, (2004).

[20] A.C.Q. Ladeira, C.A. Morais, "Uraniumrecovery from industrialeffluent by ionexchangecolumnexperiments "Minerals Engineering, 18, 1337-1340, (2005).

[21] H. Tavakoli, H. Sepehrian, F. Semnani, M. Samadfam, "Recovery of uranium from UCFliquidwaste by anionexchangeresinCG-400: Breakthrough curves, elutionbehavior and modelingstudies" Annals of Nuclear Energy, 54, 149153, (2013)

[22] Z. Marczenko and M. Balcerzak: separation, preconcentration and Spectrophotometyin Inorganic Analysis. Analytical Spectroscopy Library,10,(2000), p. 446.

\section{Publish your research article in AIJR journals-}

$\checkmark$ Online Submission and Tracking

$\checkmark$ Peer-Reviewed

$\checkmark$ Rapid decision

$\checkmark \quad$ Immediate Publication after acceptance

$\checkmark \quad$ Articles freely available online

$\checkmark \quad$ Retain full copyright of your article.

Submit your article at journals.aijr.in

Publish your books with AIJR publisher-

$\checkmark \quad$ Publish with ISBN and DOI.

$\checkmark$ Publish Thesis/Dissertation as Monograph.

$\checkmark$ Publish Book Monograph.

$\checkmark$ Publish Edited Volume/ Book.

$\checkmark$ Publish Conference Proceedings

$\checkmark \quad$ Retain full copyright of your books.

Submit your manuscript at books.aijr.org 